\title{
ELEMENTI KULTURE I CIVILIZACIJE U UDŽBENIKU ZA NJEMAČKI JEZIK MENSCHEN A2
}

\begin{abstract}
APSTRAKT: U radu se: 1) prezentuje uloga elemenata kulture i civilizacije u nastavi stranog jezika kako bi se uočio njihov značaj i obligatornost u nastavnom procesu, $s$ obzirom da su jezik i kultura usko povezane sastavnice ljudskog bivstvovanja; 2) analizira udžbenik Menschen A2, koji se koristi u nastavi njemačkog kao stranog jezika u mnogim eminentnim školama stranih jezika, kako bi se moglo doći do zaključka da li navedeni udžbenik sadrži dovoljno materijala u kom se tretiraju elementi kulture i civilizacije; 3) klasificiraju elementi kulture i civilizacije ekscerpirani iz analiziranog udžbenika kako bi se došlo do odgovora na pitanje: da li su zastupljena sva tri ključna pristupa (kognitivni, komunikativni i interkulturalni) prilikom obrade sadržaja civilizacije u analiziranom udžbeniku. Analiza je pokazala da analizirani udžbenik sadrži dovoljno zadataka i vežbi iz oblasti kulture i civilizacije, te da su u obradi ovih sadržaja podjednako zastupljena sva tri navedena pristupa.
\end{abstract}

Ključne riječi: njemački jezik, didaktika, metodika nastave stranog jezika, kultura i civilizacija.

\section{ELEMENTS OF CULTURE AND CIVILIZATION IN A GERMAN LANGUAGE TEXTBOOK MENSCHEN A2}

\begin{abstract}
The paper: 1) presents the role of elements of culture and civilization in foreign language teaching, in order to notice their importance and obligatoriness in the teaching process, since language and culture are closely related components of human existence; 2) analyzes the textbook Menschen A2, which is used in teaching German as a foreign language in many eminent foreign language schools, to show the representation of elements of culture and civilization in the textbook; 3) classifies the elements of culture and civilization excerpted from the analyzed textbook in order to answer the question: are all three key approaches (cognitive, communicative and intercultural) represented in the treatment of civilization in the analyzed textbook? The analysis shows that the textbook contains enough tasks and exercises in the field of culture and civilization and that all three of these approaches are equally represented in the treatment of these contents.
\end{abstract}

Key words: German language, didactics, foreign language teaching methodology, culture and civilization. 


\section{UVOD}

Poznata je činjenica da uspješnoj komunikaciji među ljudima doprinosi i razumijevanje kulturnih specifičnosti nekog društva. Još od antike govori se o važnosti kulturnih sadržaja prilikom učenja i podučavanja nekih od stranih jezika.

U nastavi stranih jezika dugo vremena su kultura i podučavanje sadržaja koji se odnose na kulturni segment nekog društva bili zapostavljeni. Ono što se moglo pronaći u udžbenicima bili su činjenični podaci o zemlji i stanovništu stranog jezika. U posljednje vrijeme metodika nastave stranih jezika se intenzivnije posvećuje integriranju interkulturalnosti $u$ nastavu stranih jezika, čemu doprinosi i fenomen globalizacije, koja ne prepoznaje granice i ograničenja, stereotipiju, etnocentrizam, predrasude i sl.

Bez poučavanja kulture, poučavanje stranog jezika je nepotpuno, s obzirom da ljudska priroda ne postoji odvojeno od kulture, pa je samim tim i učenje nekog stranog jezika istovremeno i poimanje prirode drugih ljudi.

\section{2. ŠTA JE TO KULTURA?}

Mnogi autori smatraju da su promišljanja o kulturi i njenom definiranju vrlo nepregledna, te da ih ima previše, što na svojevrstan način otežava prenošenje znanja o kulturi i civilizaciji u nastavi stranog jezika (Hansen 2000: 234; Holzmüller 1997: 5574).

Podsjećamo na podjelu definiranja pojma kultura autora Hofstedea na: kultura jedan ili Kultura koja se piše velikim početnim slovom i kultura dva koja se piše malim početnim slovom (Hofstede 1991: 15-19). Kultura sa velikim početnim slovom obuhvata sva postignuća unutar književnosti, slikarstva, nauke, dok kultura sa malim početnim slovom podrazumijeva ponašanja i razmišljanja koja imaju predstavnici određene kulture, a na osnovu kojih se razlikuju od drugih.

Kulturu posmatramo i kao sveukupnost društvenog djelovanja, tzv. way of life (način života), koji počiva na socijalnoj interakciji (Schwend 1997: 265), te kao mrežu različitih oblasti unutar ljudskog djelovanja (Keller 1983: 200-209).

Kramš (Kramsch) (1998: 3-5) u fokus svojih promišljanja o kulturi i jeziku stavlja povezanost jezika i kulture. Elaborira to tako što smatra da jezik izražava kulturnu stvarnost, s obzirom da ljudi riječima opisuju neke činjenice, ideje i stavove. Smatra, također, da članovi određenog društva jezikom stvaraju iskustva, pa samim tim jezik na neki način i utjelovljuje kulturnu stvarnost, s jedne strane, dok s druge strane jezik simbolizira kulturnu stvarnost, jer govornici svoj maternji jezik doživljavaju kao simbol društvenog identiteta. Smatra se da su jezik i kultura usko povezane sastavnice 
ljudskog postojanja. Jezikom se odražava i izražava kultura, a kultura, s druge strane, utječe na jezik, modificira ga i daje mu formu. Dakle, jezik i kultura su dva isprepletena pojma koja se ne mogu razdvajati.

Ono što možemo konstatovati jeste da niti jedno društvo ne postoji bez kulture. Ona je osnovno distinktivno svojstvo na osnovu kog se društva razlikuju jedna od drugih. Kultura je i svojstvo svakog pojedinca koje ga razlikuje od drugog čovjeka, jer niti jedan čovjek ne dijeli u potpunosti svoja vjerovanja, mišljenja i način života sa nekim drugim čovjekom.

\section{HISTORIJAT POUČAVANJA KULTURE U NASTAVI STRANIH JEZIKA}

Historijski gledano prva metoda poučavanja stranog jezika jeste gramatičkoprijevodna metoda iz 19. stoljeća. Ovom metodu bili su uzor klasični jezici - latinski i grčki. Cilj učenja, pa i razlog učenja nekog stranog jezika u gramatičko-prijevodnom metodu bio je sticanje spoznaja o postignućima poznatih ljudi i historijskim događajima zemlje čiji se jezik poučava. Navedeni cilj postizao se čitanjem i prevođenjem književnih tekstova pisanih na stranom jeziku koji se učio - riječi su se učile napamet, kao i gramatička pravila. Možemo zaključiti da je kultura u gramatičkoprijevodnom metodu bila zastupljena samo kao sinonim za književnost, no ne i kao sastavni dio nastave stranog jezika.

Krajem 19. stoljeća nastaju i nove metode poput direktnog metoda. One nastaju sa razvojem društvenih nauka, a sa ciljem da se strani jezik uči direktno bez prenošenja maternjeg jezika. U ovoj metodi, gdje se direktno uči strani jezik, kultura se posmatrala kao način života, što odgovara Švendovoj (Schwend) definiciji pojma kultura (Schwend 1997: 265).

Polovinom 20. stoljeća strani jezik se uči putem auditivnih i vizualnih sredstava. Cilj je da se komunicira jezikom svakodnevnice, a važne su i emocije koje se ispoljavaju i neverbalnom komunikacijom (gestika, mimika), intonacijom, a kultura predstavlja sastavni dio jezika. Najadekvatnijim načinom prenošenja elemenata kulture smatraju se dijalozi, s obzirom da se na taj način učenik sučeljava sa tekstovima i situacijama iz svakodnevnog života govornika stranog jezika koji uči.

U drugoj polovini 20. stoljeća, kada se pojavljuje komunikativna metoda, važno je da se učenik zna ponašati na adekvatan način u raznim komunikacijskim situacijama. Dakle, jezik nije samo sredstvo komunikacije, nego i sredstvo društvene interakcije, te su teme koje se obrađuju usko vezane za iskustvo običnih ljudi, što omogućavaju autentični tekstovi, a samim tim se prenose društvena i kulturna pravila. Komunikativna metoda zalaže se ne samo za pismenu i usmenu komunikaciju nego i za razvijanje svijesti o postojanju izvanjezičkih fenomena i njihove kulturalne 
uvjetovanosti. Navedeni fenomeni tipični su za svako društvo, a ukoliko ih ne poznajemo i pored dobrog poznavanja jezika, mogu se desiti nesporazumi zbog različitosti u kulturama.

Zaključno se može reći da komunikativna metoda uključuje u nastavu stranih jezika jezičku, ali i izvanjezičku dimenziju, kako bi se izbjegli eventualni nesporazumi zbog različitosti u kulturama.

\section{KLASIFIKACIJA KULTURE I CIVILIZACIJE U NASTAVI STRANOG JEZIKA}

Jezik je dio kulture jednog naroda i zbog toga je teško zamisliti nastavu stranog jezika odvojeno od kulture naroda kojima je taj jezik maternji. Ponekad će ljudi biti tolerantni prema gramatičkim greškama stranaca, dok će biti vrlo osjetljivi kad je riječ o nepoštivanju običaja. Možemo, dakle, reći da se u nastavi stranog jezika ne prenosi samo jezik, nego i uslovi i životne okolnosti stanovnika zemlje u kojoj se strani jezik govori, politička, ekonomska, kulturna dešavanja. Prenošenje takvog znanja naziva se „kultura i civilizacija”, a u njemačkoj stručnoj literaturi „Landeskunde” (Heyd 1990: 47).

Nastava kulture i civilizacije stranog jezika je najzahtjevniji segment unutar procesa učenja stranog jezika, jer sa tim dijelom nastave nikada nismo obradili sve, nikad nismo došli do kraja ili cilja. Ona uvijek obuhvata vlastita stajališta i ono što nam je strano, zbog čega je i nazivamo interkulturalnom. A obje različite strane se permanentno mijenjaju, htjeli mi to ili ne. Sve navedeno kulturu i civilizaciju razlikuje od drugih nastavnih sadržaja kao što su gramatika, fonetika, a ona postaje priča bez kraja (,unendliche Geschichte”) u nastavi stranog jezika (Pauldrach 1994: 4-15).

Sa običajima i načinom života izvornih govornika učenici se upoznaju na različite načine:

- korišćenjem tekstova kojima se prenose činjenice i daju informacije (kognitivni pristup);

- korišćenjem autentičnih tekstova ili simulirano autentičnih tekstova ${ }^{1}$ iz čijeg se konteksta mogu izvući određeni zahtjevi i steći komunikativna kompetencija (komunikativni pristup);

\footnotetext{
${ }^{1}$ Ovdje treba napomenuti da se autentični tekstovi koriste u sva tri pristupa, a ne samo u komunikativnom pristupu.
} 
- uočavanjem razlika između vlastite kulture i kulture naroda čiji se jezik uči (interkulturalni pristup) (Heyd, 1990: 47-56).

Kognitivni pristup se često kritikuje zbog svojih previsokih zahtjeva koji se postavljaju pred učenike. Pikt (Picht) (1989: 54-60) u svojim radovima, također, kritikuje kognitivni pristup kada je u pitanju nastava civilizacije i kulture, s obzirom da je, kako on tvrdi, ovaj pristup „enciklopedijski” i izdvaja samo određene činjenice. On smatra da su sve manifestacije kulture dijelovi jedne cjeline, čiji oblik i značenje je uvjetovano zajedničkim djelovanjem historijskih i funkcionalnih okolnosti između različitih aspekata određene kulture, te se kognitivni pristup ne treba izdvajati kao jedinka, nego je dio sistema.

Primjer kognitivnog pristupa²:

${ }^{2}$ Slika preuzeta sa:

http://www.goethe.de/ins/by/pro/lewis/didakt/Didaktisierung_Deutschland_von_oben_fuer _Kinder_erzaelt_Mai.pdf 
Deutschlard woh obenj/Cerhard Laurser, Mantred Mai Didaktiniert wan Cialine Korver
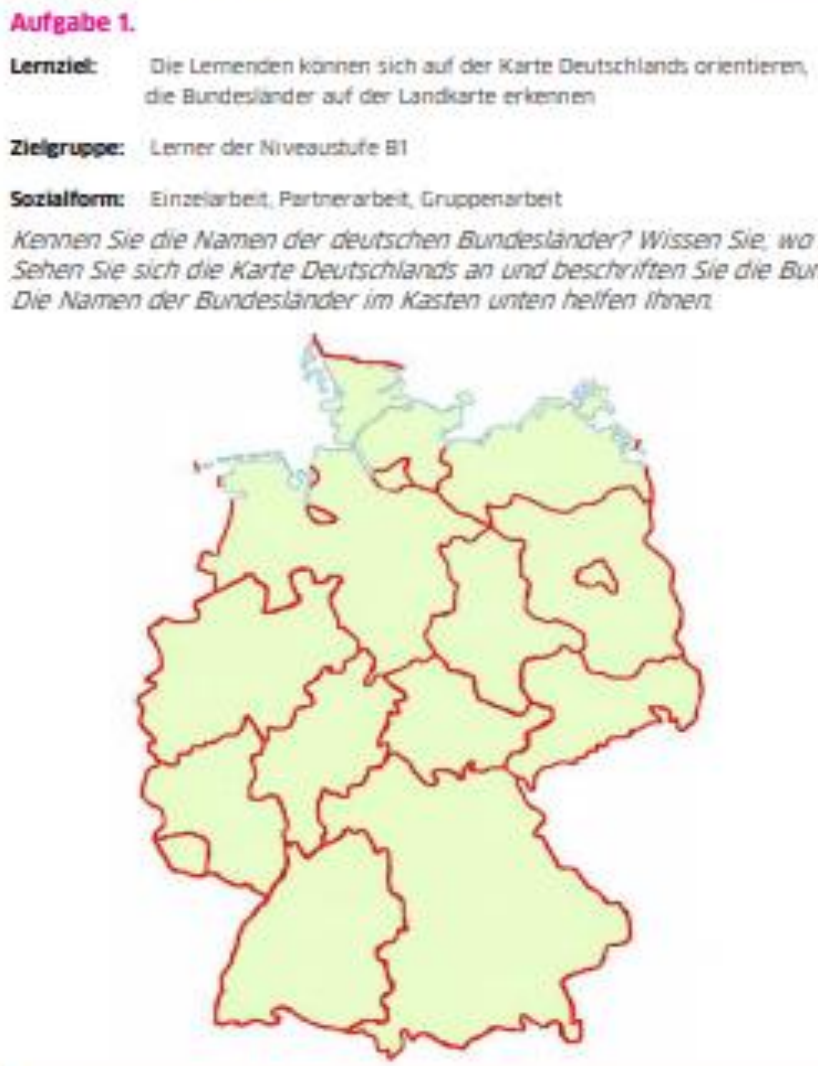

Baden-Wurttemberg Bayern Beriln Brandenburg Bremen Hambure Hessen

Mecklenburg-Vorpommern Niedersachsen Nordrhein-Westtalen Rheinland-Ptalz

Saarland Sachsen Sachsen-Anhalt Schleswig-Holstein Thoringen

wow pasthe, de/lewis

Q 2012 Qovete-inutitut Mink.

Slika 1. Kognitivni pristup

Zadatak učenika jeste da na karti Njemačke upišu nazive pokrajina. Kao pomoć dati su nazivi 16 pokrajina koji se nalaze ispod karte.

Komunikativni pristup počiva na tekstovima svakodnevnice, a Pikt (1989: 57) upravo tu vidi ,problem”, jer, kako on smatra, svakodnevnica uopće nije svakodnevna. Ono što je po njemu problematično jeste činjenica da je 
svakodnevnica satkana od spontanosti, a samim tim neplanirana spontanost je prožeta kompleksnošću koja proizlazi iz nesvjesnih situacija iz svakodnevnog života.

Primjer komunikativnog pristupa ${ }^{3}$ :

Al | Alltag in Österreich

\section{Kommunikation im Alltag}

\begin{tabular}{|c|c|}
\hline $\begin{array}{l}\text { 1. Sie sind im Bus und möchten } \\
\text { aussteigen. Sie sitzen weit vom } \\
\text { Halteknopf entfernt. }\end{array}$ & $\begin{array}{l}\text { a) Entschuldigen Sie, wo ist } \\
\text { diese Straße? }\end{array}$ \\
\hline $\begin{array}{l}\text { 2. Sie haben einen Kinderwagen. Die } \\
\text { Straßenbahn kommt. }\end{array}$ & b) Kann ich dir helfen? \\
\hline $\begin{array}{l}\text { 3. Sie sitzen in der Straßenbahn. Ein } \\
\text { alter Mann mit einem Stock steigt } \\
\text { ein. Es ist kein Platz mehr frei. }\end{array}$ & c) Möchten Sie sich setzen? \\
\hline 4. Sie suchen eine Adresse. & $\begin{array}{l}\text { d) Können Sie mir bitte das } \\
\text { Öl heruntergeben? }\end{array}$ \\
\hline $\begin{array}{l}\text { 5. Sie möchten im Supermarkt Öl } \\
\text { kaufen. Es ist zu weit oben im Regal. }\end{array}$ & e) Brauchen Sie Hilfe? \\
\hline $\begin{array}{l}\text { 6. Sie sehen ein kleines Kind. Es sitzt } \\
\text { alleine am Gehsteig und weint. }\end{array}$ & $\begin{array}{l}\text { f) Können Sie mir bitte } \\
\text { beim Einsteigen mit dem } \\
\text { Kinderwagen helfen? }\end{array}$ \\
\hline $\begin{array}{l}\text { 7. Ihre alte Nachbarin trägt eine } \\
\text { schwere Tasche die Stiegen hoch. }\end{array}$ & $\begin{array}{l}\text { g) Könnten Sie bitte für mich } \\
\text { drücken? }\end{array}$ \\
\hline
\end{tabular}

Slika 2. Komunikativni pristup

${ }^{3}$ Slika preuzeta sa:

https://sprachportal.integrationsfonds.at/fileadmin/user_upload/2015/Materialien\%20Schwe rpunkt\%20Deutsch/Kommunikation_im_Alltag.pdf 
Zadatak učenika jeste da svakoj od ponuđenih situacija u kojima se mogu naći u svakodnevnom životu pridruže odgovarajuće pitanje.

Kod interkulturalnog pristupa Timi (Thimme) (1995: 131-137) kritizira što se on posmatra odvojeno od druga dva navedena pristupa. On smatra da interkulturalni pristup obuhvata ciljeve koji su sastavni dio kognitivnog ili komunikativnog pristupa. Na kraju zaključuje da nema smisla da se interkulturalni pristup posmatra i izučava izolovano od drugih pristupa i ciljeva.

Primjer interkulturalnog pristupa ${ }^{4}$ :

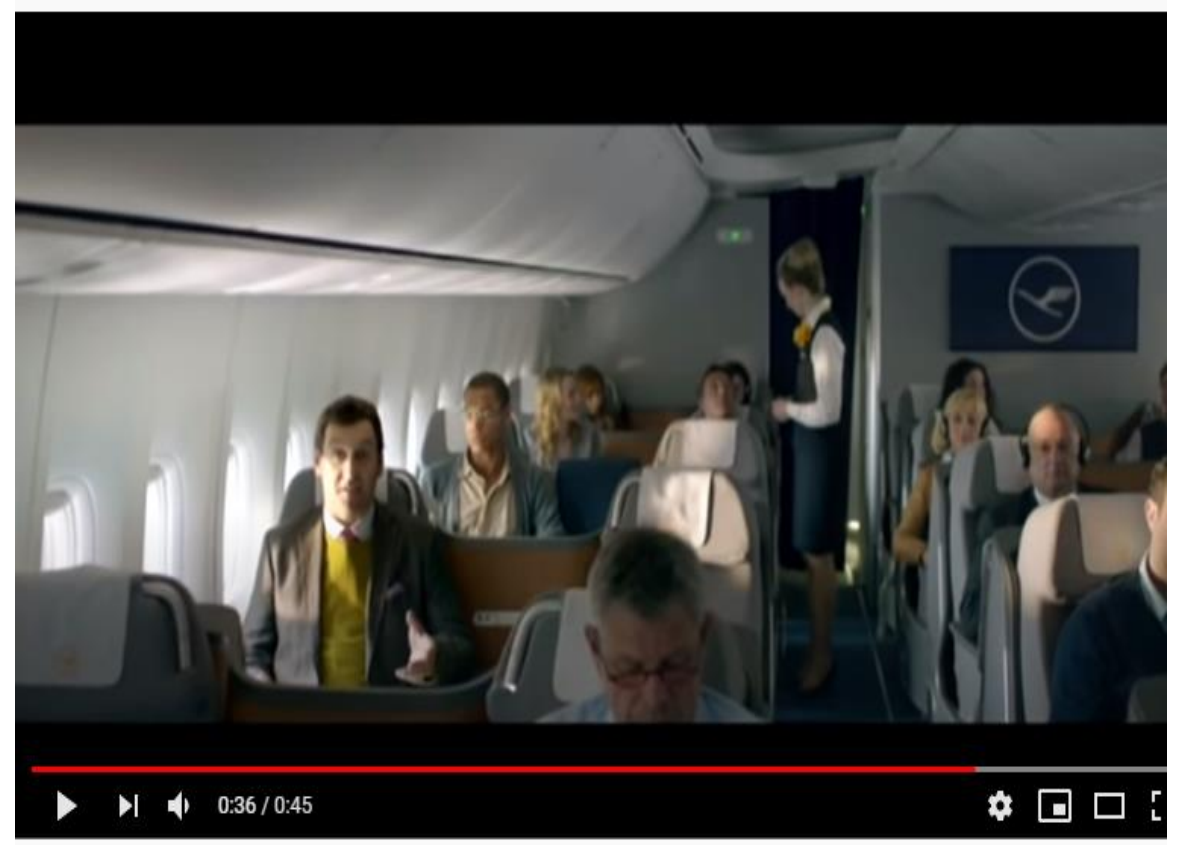

Lufthansa Werbung 2013 französischer Fluggast - "Diese deutschen immer so genau"

171.574 pregleda - 25. maj 2013.

Slika 3. Interkulturalni pristup

Radi se o reklami njemačke aviokompanije Lufthansa u kojoj francuski putnik sa oduševljenjem i na jedan vrlo simpatičan način priča o vrlinama Nijemaca, kao što su: preciznost, tačnosti i sl. Ovaj video može poslužiti kao povod

\footnotetext{
${ }^{4}$ Slika preuzeta sa:

https://www.youtube.com/watch?time_continue $=2 \& v=K w T 0 J d k W-u E \&$ feature=emb_title
} 
da se navedene vrline porede sa karakteristikama koje važe za Nijemce u zemlji u kojoj se uči njemački jezik, te da se porede sa vlastitim vrlinama ili manama.

Zadatak nastavnika u nastavi stranog jezika je da kod učenika stvori objektivan stav prema razlikama koje postoje u kulturama stranog (ciljnog) i maternjeg jezika. Nastavnik ne treba dozvoliti da se donose pogrešni zaključci, da strana kultura manje ili više vrijedi od vlastite. Cilj nastave stranog jezika jeste da se učenici odgajaju u duhu internacionalizma i uvažavanja različitosti. Starosna dob i ciljevi nastave utiču na količinu podataka iz civilizacije. Tekstovi koji se trebaju koristiti su autentični tekstovi, rjeđe književni tekstovi, jer se oni znatno razlikuju od svakodnevnog govora, a književni jezik je pretežak za prosječnog govornika, ali to ne znači da se trebaju u potpunosti isključiti iz nastavnog procesa (Heyd 1990: 47-56).

\section{ULOGA UDŽBENIKA U PRENOŠENJU ELEMENATA KULTURE I CIVILIZACIJE U NASTAVI STRANOG JEZIKA}

Stariji udžbenici u nastavi stranog jezika su, unutar segmenata kulture i civilizacije, tretirali uglavnom teme koje su obuhvatale specifičnosti vezane za kulturu zemlje u kojoj se strani jezik govori kao maternji. U posljednje vrijeme udžbenici se fokusiraju na teme koje su univerzalne, a sa ciljem izbjegavanja mogućeg konflikta. Trenutni trend koji se javlja u tretiranju elemenata kulture i civilizacije u nastavi stranog jezika je povezan sa globalizacijskim procesima. Altmajer (Altmayer) (2017: 17-19), međutim, smatra da je učenje stranog jezika individualan proces, te da udžbenici ne treba da izbjegavaju tekstove koji su specifični za određenu kulturu, nego da se baš takve tekstove treba ugrađivati $u$ udžbenike, a da se oni koji uče individualno suočavaju za izazovima koje predstavlja kulturna globalizacija za predmet Njemački kao strani jezik.

Opservacija udžbenika za njemački kao strani jezik potvrđuje trend, koji zagovara univerzalne teme u sklopu obrade elemenata kulture i civilizacije, pa je takav slučaj i sa udžbenikom Menschen. Teme koje tretiraju specifičnosti određene kulture zamjenjuju se univerzalnim problemima socijalne interakcije (Altmayer 2017: 16). Međutim, istraživanja pokazuju da, i pored fokusa na univerzalne teme, nije moguće izbjeći konfliktne situacije (Braun-Podeschwa et al. 2014: 36-38).

Ilustracije u udžbeniku Menschen Bl kojima se obrađuje tema Einladung (pozivnica) idu u prilog tome. Naime, stvara se slika o tome da su ljudi koji žive u njemačkom govornom području isključivo bijelci, da su rijetko kada stariji od 35 godina, da pripadaju, uglavnom, imućnijem građanskom staležu. Teško da će se sa ovakvim porukama moći poistovijetiti oni koji uče njemački jezik u siromašnijim 
zemljama, kao što su Afrika ili Meksiko, a što izdavač podvlači u namjeni i cilju ovog udžbenika (Braun-Podeschwa et al. 2014: 16).

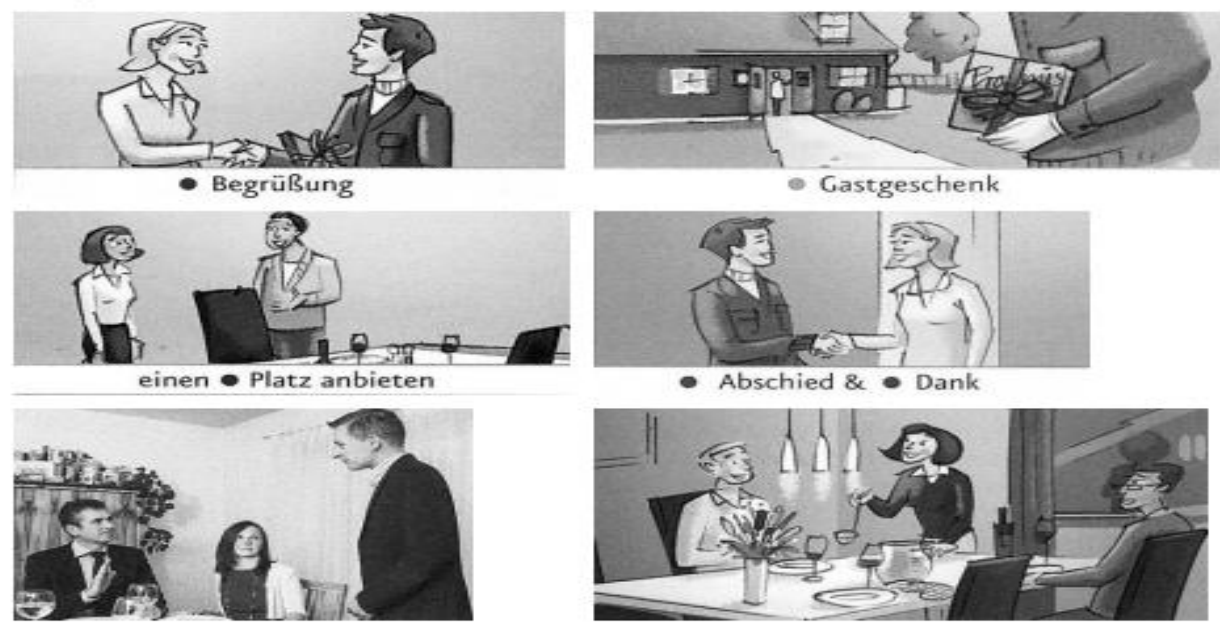

Slika 4. Menschen B1.1 (Braun-Podeschwa et al. 2014: 16)

\section{ANALIZA ELEMENATA KULTURE I CIVILIZACIJE U UDŽBENIKU MENSCHEN A2}

U ovom dijelu rada želi se detaljnom analizom udžbenika Menschen A2, koji se ubraja među najfrekventnije udžbenike koji se koriste u nastavi njemačkog kao stranog jezika, provjeriti da li navedeni udžbenik sadrži dovoljno materijala kojim se tretiraju elementi kulture i civilizacije, te da li su zastupljena i koliko sva tri ključna pristupa (kognitivni, komunikativni i interkulturalni) prilikom obrade kulture i civilizacije. Ono što je pohvalno jeste da navedeni udžbenik kao sastavni dio sadrži posebne module koji tretiraju kulturu i civilizaciju. U ovom udžbeniku se nalazi osam takvih modula sa ukupno 16 zadataka. Istraživanje je sprovedeno tako da se za svaki zadatak detaljno opisala aktivnost, cilj te aktivnosti, pristup koji se tretira, te obrazloženje.

U sljedećoj tabeli detaljno su izanalizirani svi zadaci kojima je $\mathrm{u}$ fokusu obrada kulture i civilizacije u udžbeniku Menschen A2 (Projekt Landeskunde,) koji se koristi za nastavu stranog jezika, tačnije njemačkog kao stranog jezika.

\begin{tabular}{lllll}
\hline Zadatak/vježba & Aktivnost & Cilj/kompetencije & Pristup & Obrazloženje \\
\hline Str. 23. Modul 1 & Učenici čitaju & Razvijanje čitanja & Kognitivni & Radi se o podacima, \\
Projekt & tekst o & i razumijevanja; & pristup & informacijama, \\
Landeskunde & porodici Man & Vježbanje & (književnost) & činjenicama koje se \\
Zadatak 1. & (Mann), iz & izgovora; & & odnose na život i djelo \\
\hline
\end{tabular}




\begin{tabular}{|c|c|c|c|c|}
\hline & $\begin{array}{l}\text { koje potječu } \\
\text { braća Man, } \\
\text { poznati } \\
\text { njemački } \\
\text { književnici. } \\
\text { Njihov je } \\
\text { zadatak da } \\
\text { čitaju tekst } \\
\text { podijeljen u } \\
\text { tri dijela: o } \\
\text { porodici Man, } \\
\text { o Hajnrihu } \\
\text { Manu } \\
\text { (Heinrichu } \\
\text { Mannu), o } \\
\text { Tomasu } \\
\text { Manu } \\
\text { (Thomasu } \\
\text { Mannu), a } \\
\text { potom da } \\
\text { unesu } \\
\text { podatke o } \\
\text { dvojici pisaca } \\
\text { u tabelu ispod } \\
\text { teksta. }\end{array}$ & $\begin{array}{l}\text { Aktiviranje općeg } \\
\text { znanja; } \\
\text { Kultura i } \\
\text { civilizacija: } \\
\text { njemački } \\
\text { književnici }\end{array}$ & & $\begin{array}{l}\text { Hajnriha i Tmasa Mana, } \\
\text { poznatih književnika iz } \\
\text { Njemačke. }\end{array}$ \\
\hline $\begin{array}{l}\text { Str. 23. Modul } 1 \\
\text { Projekt } \\
\text { Landeskunde } \\
\text { Zadatak } 2 .\end{array}$ & $\begin{array}{l}\text { Učenici treba } \\
\text { da se } \\
\text { informišu i u } \\
\text { tabelu unesu } \\
\text { podatke o } \\
\text { nekoj } \\
\text { poznatoj } \\
\text { porodici } \\
\text { (njemačko } \\
\text { govorno } \\
\text { područje ili } \\
\text { domovina), } \\
\text { po uzoru na } \\
\text { tabelu iz } \\
\text { prethodnog } \\
\text { zadatka, te da } \\
\text { zabilješke o } \\
\text { porodici koju } \\
\text { su izabrali } \\
\text { elaboriraju } \\
\text { usmeno. }\end{array}$ & $\begin{array}{l}\text { Razvijanje } \\
\text { pisanja; } \\
\text { Razvijanje govora; } \\
\text { Aktiviranje općeg } \\
\text { znanja; } \\
\text { Kultura i } \\
\text { civilizacija: } \\
\text { poznate porodice } \\
\text { iz njemačkog } \\
\text { govornog } \\
\text { područja, iz } \\
\text { domovine. }\end{array}$ & $\begin{array}{l}\text { Interkulturalni } \\
\text { pristup } \\
\text { (2. svjetski rat, } \\
\text { emigriranje) } \\
\end{array}$ & $\begin{array}{l}\text { Radi se o poznatim } \\
\text { ličnostima iz Njemačke, } \\
\text { njemačkog govornog } \\
\text { područja i onih iz } \\
\text { domovine, da li su i } \\
\text { koliko su poznati } \\
\text { internacionalno, te da li } \\
\text { su emigrirali, kao braća } \\
\text { Mann. }\end{array}$ \\
\hline
\end{tabular}




\begin{tabular}{|c|c|c|c|c|}
\hline $\begin{array}{l}\text { Str. 39. Modul } 2 \\
\text { Projekt } \\
\text { Landeskunde } \\
\text { Zadatak } 1 .\end{array}$ & $\begin{array}{l}\text { Učenici treba } \\
\text { da pročitaju } \\
\text { tekst o dvorcu } \\
\text { Šenbrun } \\
\text { (Schönbrunn) } \\
\text { u Beču, te da } \\
\text { svakom } \\
\text { odlomku } \\
\text { pridruže } \\
\text { jednu od } \\
\text { ponuđenih } \\
\text { slika. }\end{array}$ & $\begin{array}{l}\text { Razvijanja } \\
\text { vještine čitanja i } \\
\text { razumijevanja; } \\
\text { Vježbanje } \\
\text { izgovora; } \\
\text { Aktiviranje općeg } \\
\text { znanja; } \\
\text { Kultura i } \\
\text { civilizacija: } \\
\text { austrijski glavni } \\
\text { grad i njegove } \\
\text { znamenitosti. }\end{array}$ & $\begin{array}{l}\text { Kognitivni } \\
\text { pristup } \\
\text { (historija) }\end{array}$ & $\begin{array}{l}\text { Radi se o historijskim } \\
\text { podacima, činjenicama i } \\
\text { informacijama o } \\
\text { znamenitostima glavnog } \\
\text { grada Austrije, Beča. }\end{array}$ \\
\hline $\begin{array}{l}\text { Str. 39. Modul } 2 \\
\text { Projekt } \\
\text { Landeskunde } \\
\text { Zadatak } 2 .\end{array}$ & $\begin{array}{l}\text { Učenici treba } \\
\text { da izaberu } \\
\text { neku drugu } \\
\text { znamenitost u } \\
\text { Beču, te da } \\
\text { sakupe što } \\
\text { više } \\
\text { informacija i } \\
\text { slika o toj } \\
\text { znamenitosti, } \\
\text { vodeći } \\
\text { bilješke. } \\
\text { Nakon toga, } \\
\text { pišu tekst, } \\
\text { vodeći se } \\
\text { zadatkom br. } \\
\text { 1. i } \\
\text { prezentiraju } \\
\text { znamenitost } \\
\text { za koju su se } \\
\text { odlučili } \\
\text { ostalim } \\
\text { učenicima. }\end{array}$ & $\begin{array}{l}\text { Razvijanje } \\
\text { vještine čitanja i } \\
\text { razumijevanja; } \\
\text { Razvijanje } \\
\text { vještine pisanja; } \\
\text { Razvijanje } \\
\text { vještine govora; } \\
\text { Aktiviranje općeg } \\
\text { znanja; } \\
\text { Kultura i } \\
\text { civilizacija: } \\
\text { austrijski glavni } \\
\text { grad i njegove } \\
\text { znamenitosti. }\end{array}$ & $\begin{array}{l}\text { Kognitivni } \\
\text { pristup } \\
\text { (historija) }\end{array}$ & $\begin{array}{l}\text { Radi se o podacima, } \\
\text { činjenicama i } \\
\text { informacijama o } \\
\text { znamenitostima glavnog } \\
\text { grada Austrije, Beča. }\end{array}$ \\
\hline $\begin{array}{l}\text { Str. 55. Modul } 3 \\
\text { Projekt } \\
\text { Landeskunde } \\
\text { Zadatak } 1 .\end{array}$ & $\begin{array}{l}\text { Učenici čitaju } \\
\text { tekst o načinu } \\
\text { pranja odjeće } \\
\text { prije } 100 \\
\text { godina i } \\
\text { danas, te se } \\
\text { iznosi } \\
\text { statistika o } \\
\text { posjedu veš } \\
\text { mašine na } \\
\text { njemačkom }\end{array}$ & $\begin{array}{l}\text { Razvijanje } \\
\text { vještine čitanja i } \\
\text { razumijevanja; } \\
\text { Uvježbavanje } \\
\text { izgovora; } \\
\text { Aktiviranje općeg } \\
\text { znanja; } \\
\text { Kultura i } \\
\text { civilizacija: pranje } \\
\text { veša na } \\
\text { njemačkom }\end{array}$ & $\begin{array}{l}\text { Kognitivni } \\
\text { pristup } \\
\text { (historija, } \\
\text { izumi) }\end{array}$ & $\begin{array}{l}\text { Iznose se podaci i } \\
\text { činjenice o pranju veša } \\
\text { prije } 100 \text { godina i danas } \\
\text { u zemljama njemačkog } \\
\text { govornog područja sa } \\
\text { statistikama. }\end{array}$ \\
\hline
\end{tabular}




\begin{tabular}{|c|c|c|c|c|}
\hline & $\begin{array}{l}\text { govornom } \\
\text { području. } \\
\text { Njihov } \\
\text { zadatak je da, } \\
\text { nakon čitanja, } \\
\text { označe } \\
\text { rečenice } \\
\text { ispod teksta } \\
\text { kao tačne ili } \\
\text { netačne. }\end{array}$ & $\begin{array}{l}\text { govornom } \\
\text { području prije } 100 \\
\text { godina i danas. }\end{array}$ & & \\
\hline $\begin{array}{l}\text { Str. 55. Modul } 3 \\
\text { Projekt } \\
\text { Landeskunde } \\
\text { Zadatak } 2 .\end{array}$ & $\begin{array}{l}\text { Učenici biraju } \\
\text { temu o životu } \\
\text { prije } 100 \\
\text { godina u } \\
\text { domovini (od } \\
\text { ponuđene tri) } \\
\text { i sakupljaju } \\
\text { informacije i } \\
\text { slike na } \\
\text { internetu, u } \\
\text { biblioteci. } \\
\text { Nakon toga, } \\
\text { pišu tekstove } \\
\text { ispod slika i } \\
\text { prave plakat } \\
\text { koji izlažu u } \\
\text { učionici. }\end{array}$ & $\begin{array}{l}\text { Razvijanje } \\
\text { vještine čitanja i } \\
\text { razumijevanja; } \\
\text { Razvijanje } \\
\text { vještine pisanja; } \\
\text { Aktiviranje općeg } \\
\text { znanja; } \\
\text { Kultura i } \\
\text { civilizacija: život } \\
\text { u domovini prije } \\
100 \text { godina i život } \\
\text { na njemačkom } \\
\text { govornom } \\
\text { području prije } 100 \\
\text { godine u različitim } \\
\text { sferama. }\end{array}$ & $\begin{array}{l}\text { Interkulturalni } \\
\text { pristup } \\
\text { (razumijevanje } \\
\text { okolnosti prije } \\
100 \text { godina u } \\
\text { Njemačkoj i } \\
\text { sada, te } \\
\text { povezivanje sa } \\
\text { životom u } \\
\text { domovini prije } \\
\text { i danas). }\end{array}$ & $\begin{array}{l}\text { Život u domovini prije } \\
100 \text { godina u poređenju } \\
\text { sa životom na } \\
\text { njemačkom govornom } \\
\text { području i danas. }\end{array}$ \\
\hline $\begin{array}{l}\text { Str. } 71 . \text { Modul } 4 \\
\text { Projekt } \\
\text { Landeskunde } \\
\text { Zadatak } 1 .\end{array}$ & $\begin{array}{l}\text { Učenici čitaju } \\
\text { kritiku o } \\
\text { restoranu u } \\
\text { Hamburgu, a } \\
\text { nakon toga } \\
\text { popunjavaju } \\
\text { tabelu o tome } \\
\text { kako su } \\
\text { ocijenjeni } \\
\text { hrana, } \\
\text { atmosfera, } \\
\text { usluga i } \\
\text { cijene. }\end{array}$ & $\begin{array}{l}\text { Razvijanje } \\
\text { vještine čitanja i } \\
\text { razumijevanja; } \\
\text { Uvježbavanje } \\
\text { izgovora; } \\
\text { Aktiviranje } \\
\text { predznanja; } \\
\text { Kultura i } \\
\text { civilizacija: } \\
\text { ugostiteljstvo u } \\
\text { Njemačkoj. }\end{array}$ & $\begin{array}{l}\text { Komunikativni } \\
\text { pristup } \\
\text { (situacija iz } \\
\text { svakodnevnog } \\
\text { života). }\end{array}$ & $\begin{array}{l}\text { Tekst iz svakodnevnog } \\
\text { života o ugostiteljstvu. }\end{array}$ \\
\hline $\begin{array}{l}\text { Str. } 71 . \text { Modul } 4 \\
\text { Projekt } \\
\text { Landeskunde } \\
\text { Zadatak } 2 .\end{array}$ & $\begin{array}{l}\text { Učenici treba } \\
\text { da rade u } \\
\text { grupama. } \\
\text { Odlučuju se } \\
\text { za neki } \\
\text { domaći }\end{array}$ & $\begin{array}{l}\text { Razvijanje } \\
\text { vještine govora; } \\
\text { Razvijanje } \\
\text { vještine pisanja; } \\
\text { Kultura i } \\
\text { civilizacija: }\end{array}$ & $\begin{array}{l}\text { Interkulturalni } \\
\mathrm{i} \\
\text { komunikativni } \\
\text { pristup }\end{array}$ & $\begin{array}{l}\text { Komunikacija o temi iz } \\
\text { svakodnevnog života, te } \\
\text { poređenje ugostiteljstva } \\
\text { u Njemačkoj i } \\
\text { domovini. }\end{array}$ \\
\hline
\end{tabular}




\begin{tabular}{|c|c|c|c|c|}
\hline & $\begin{array}{l}\text { restoran i u } \\
\text { skladu sa } \\
\text { prethodnim } \\
\text { tekstom i } \\
\text { zadatkom } \\
\text { rade kritiku, } \\
\text { razgovarajući, } \\
\text { zapisujući } \\
\text { bilješke, a } \\
\text { onda restoran } \\
\text { za koji su se } \\
\text { odlučili } \\
\text { prezentiraju } \\
\text { ostalim } \\
\text { učenicima u } \\
\text { razredu. }\end{array}$ & $\begin{array}{l}\text { ugostiteljstvo u } \\
\text { vlastitoj zemlji i } \\
\text { ugostiteljstvo u } \\
\text { Njemačkoj. }\end{array}$ & & \\
\hline $\begin{array}{l}\text { Str. 23. Modul } 5 \\
\text { Projekt } \\
\text { Landeskunde } \\
\text { Zadatak } 1 .\end{array}$ & $\begin{array}{l}\text { Učenici čitaju } \\
\text { tekst sa } \\
\text { interneta o } \\
\text { kursevima } \\
\text { njemačkog } \\
\text { jezika u } \\
\text { Berlinu, a } \\
\text { nakon čitanja } \\
\text { treba da } \\
\text { označe one } \\
\text { izjave ispod } \\
\text { teksta koje su } \\
\text { tačne. }\end{array}$ & $\begin{array}{l}\text { Razvijanje } \\
\text { vještine čitanja i } \\
\text { razumijevanja; } \\
\text { Vježbanje } \\
\text { izgovora; } \\
\text { Kultura i } \\
\text { civilizacija: učenje } \\
\text { njemačkog jezika } \\
\text { u Njemačkoj. }\end{array}$ & $\begin{array}{l}\text { Komunikativni } \\
\text { pristup } \\
\text { (situacija iz } \\
\text { svakodnevnog } \\
\text { života) }\end{array}$ & $\begin{array}{l}\text { Tekst koji se obrađuje } \\
\text { ne tretira činjenice o } \\
\text { njemačkom govornom } \\
\text { području, niti nudi } \\
\text { shvatanje/razumijevanje } \\
\text { kulturnih specifičnosti } \\
\text { njemačkog govornog } \\
\text { područja. Radi se o } \\
\text { autentičnom tekstu iz } \\
\text { svakodnevnog života. }\end{array}$ \\
\hline $\begin{array}{l}\text { Str. 23. Modul } 5 \\
\text { Projekt } \\
\text { Landeskunde } \\
\text { Zadatak } 2 .\end{array}$ & $\begin{array}{l}\text { Učenici treba } \\
\text { da rade u } \\
\text { grupama i da } \\
\text { osmisle svoj } \\
\text { "perfektni” } \\
\text { kurs } \\
\text { njemačkog } \\
\text { jezika. Isti } \\
\text { treba da } \\
\text { naprave u } \\
\text { vidu plakata, } \\
\text { kojeg } \\
\text { prezentiraju } \\
\text { na nastavi. }\end{array}$ & $\begin{array}{l}\text { Razvijanje } \\
\text { vještine govora; } \\
\text { Razvijanje } \\
\text { vještine pisanja; } \\
\text { Kultura i } \\
\text { civilizacija: } \\
\text { komunikacija o } \\
\text { učenju njemačkog } \\
\text { jezika na } \\
\text { njemačkom } \\
\text { govornom } \\
\text { području. }\end{array}$ & $\begin{array}{l}\text { Komunikativni } \\
\text { pristup } \\
\text { (situacija iz } \\
\text { svakodnevnog } \\
\text { života, } \\
\text { komunikacija) }\end{array}$ & $\begin{array}{l}\text { Tema iz svakodnevnog } \\
\text { života o kojoj učenici } \\
\text { komuniciraju u grupama } \\
\text { (dijaloški) i ispred } \\
\text { razreda (monološki). }\end{array}$ \\
\hline $\begin{array}{l}\text { Str. 39. Modul } 6 \\
\text { Projekt } \\
\text { Landeskunde }\end{array}$ & $\begin{array}{l}\text { Učenici čitaju } \\
\text { tekst o klimi } \\
\text { u Švicarskoj, }\end{array}$ & $\begin{array}{l}\text { Razvijanje } \\
\text { vještine čitanja i } \\
\text { razumijevanja; }\end{array}$ & $\begin{array}{l}\text { Kognitivni } \\
\text { pristup } \\
\text { (geografija) }\end{array}$ & $\begin{array}{l}\text { Učenici se susreću sa } \\
\text { geografskim } \\
\text { činjenicama o }\end{array}$ \\
\hline
\end{tabular}




\begin{tabular}{|c|c|c|c|c|}
\hline Zadatak 1. & $\begin{array}{l}\text { a nakon što } \\
\text { pročitaju tekst } \\
\text { ispravljaju } \\
\text { greške u } \\
\text { rečenicama } \\
\text { koje se } \\
\text { odnose na } \\
\text { podatke u } \\
\text { tekstu. }\end{array}$ & $\begin{array}{l}\text { Razvijanje } \\
\text { vještine pisanja; } \\
\text { Vježbanje } \\
\text { izgovora; } \\
\text { Aktiviranje općeg } \\
\text { znanja iz } \\
\text { geografije; } \\
\text { Kultura i } \\
\text { civilizacija: } \\
\text { geografija } \\
\text { Švicarske. }\end{array}$ & & Švicarskoj. \\
\hline $\begin{array}{l}\text { Str. 39. Modul } 6 \\
\text { Projekt } \\
\text { Landeskunde } \\
\text { Zadatak } 2 .\end{array}$ & $\begin{array}{l}\text { Učenici biraju } \\
\text { neku } \\
\text { omiljenu } \\
\text { zemlju ili } \\
\text { svoju zemlju i } \\
\text { istražuju } \\
\text { klimu te } \\
\text { zemlje, te } \\
\text { podatke } \\
\text { evidentiraju } \\
\text { na plakatu, } \\
\text { kojeg } \\
\text { prezentiraju } \\
\text { pred } \\
\text { razredom. }\end{array}$ & $\begin{array}{l}\text { Razvijanje } \\
\text { vještine čitanja i } \\
\text { razumijevanja; } \\
\text { Razvijanje } \\
\text { vještine govora; } \\
\text { Razvijanje } \\
\text { vještine pisanja; } \\
\text { Kultura i } \\
\text { civilizacija: } \\
\text { geografija } \\
\text { domovine ili neke } \\
\text { omiljene zemlje. }\end{array}$ & $\begin{array}{l}\text { Interkulturalni } \\
\text { pristup }\end{array}$ & $\begin{array}{l}\text { Učenici istraživanjem } \\
\text { klimatskih činjenica o } \\
\text { Švicarskoj, svojoj zemlji } \\
\text { ili nekoj drugoj zemlji, } \\
\text { uče i razumijevaju } \\
\text { različitosti ili sličnosti } \\
\text { po pitanju ove } \\
\text { geografske tematike. }\end{array}$ \\
\hline $\begin{array}{l}\text { Str. 55. Modul } 7 \\
\text { Projekt } \\
\text { Landeskunde } \\
\text { Zadatak } 1 .\end{array}$ & $\begin{array}{l}\text { Učenici čitaju } \\
\text { tekst o } \\
\text { udruženju } \\
\text { koje zagovara } \\
\text { važnost } \\
\text { čitanja u } \\
\text { razvoju } \\
\text { ličnosti. } \\
\text { Navedeni su } \\
\text { podaci o } \\
\text { udruženju, } \\
\text { načinu rada, } \\
\text { važnosti } \\
\text { čitanja za } \\
\text { psiho-fizički } \\
\text { razvoj, te } \\
\text { statistiku } \\
\text { posjećenosti } \\
\text { njihovih } \\
\text { događaja. }\end{array}$ & $\begin{array}{l}\text { Razvijanje } \\
\text { vještine čitanja i } \\
\text { razumijevanja; } \\
\text { Vježbanje } \\
\text { izgovora; } \\
\text { Kultura i } \\
\text { civilizacija: } \\
\text { pedagogija u } \\
\text { Njemačkoj. }\end{array}$ & $\begin{array}{l}\text { Kognitivni } \\
\text { pristup }\end{array}$ & $\begin{array}{l}\text { Učenici se upoznaju sa } \\
\text { činjenicama, } \\
\text { informacijama i } \\
\text { podacima vezanim za } \\
\text { važnost čitanja u okviru } \\
\text { psiho-fizičkog razvoja } \\
\text { djece, te načinu } \\
\text { unapređenja istog u } \\
\text { Njemačkoj. }\end{array}$ \\
\hline
\end{tabular}




\begin{tabular}{|c|c|c|c|c|}
\hline $\begin{array}{l}\text { Str. 55. Modul } 7 \\
\text { Projekt } \\
\text { Landeskunde } \\
\text { Zadatak } 2 .\end{array}$ & $\begin{array}{l}\text { Učenici treba } \\
\text { da istraže da } \\
\text { li postoje neki } \\
\text { slični projekti } \\
\text { kojima se } \\
\text { dobrovoljno } \\
\text { unapređuje } \\
\text { čitanje, kao u } \\
\text { zadatku br. } 1 . \\
\text { i u domovini, } \\
\text { te da o tom } \\
\text { naprave } \\
\text { bilješke, da } \\
\text { napišu tekst } \\
\text { kojeg } \\
\text { prezentiraju u } \\
\text { razredu. }\end{array}$ & $\begin{array}{l}\text { Razvijanje } \\
\text { vještine čitanja i } \\
\text { razumijevanja; } \\
\text { Razvijanje } \\
\text { vještine pisanja; } \\
\text { Razvijanje } \\
\text { vještine govora; } \\
\text { Uvježbavanje } \\
\text { izgovora; } \\
\text { Kultura i } \\
\text { civilizacija: } \\
\text { udruženje u BiH } \\
\text { koje zagovara i } \\
\text { promovira čitanje } \\
\text { vs. udruženje u } \\
\text { Njemačkoj iz } \\
\text { zadatka br. } 1 .\end{array}$ & $\begin{array}{l}\text { Interkulturalni } \\
\text { pristup }\end{array}$ & $\begin{array}{l}\text { Učenici uče o } \\
\text { udruženjima u } \\
\text { Njemačkoj koja na } \\
\text { volonterskoj bazi brinu } \\
\text { o razvoju psiho-fizičkog } \\
\text { stanja djeteta kroz } \\
\text { čitanje. Postojanje slične } \\
\text { ustanove istražuju u } \\
\text { domovini, da li postoje, } \\
\text { kako rade. To sve } \\
\text { porede sa Njemačkom. }\end{array}$ \\
\hline $\begin{array}{l}\text { Str. } 71 . \text { Modul } 8 \\
\text { Projekt } \\
\text { Landeskunde } \\
\text { Zadatak } 1 .\end{array}$ & $\begin{array}{l}\text { Učenici čitaju } \\
\text { tekst o } \\
\text { agenciji koja } \\
\text { nudi } \\
\text { mogućnost } \\
\text { zapošljavanja } \\
\text { u inozemstvu, } \\
\text { a pored toga } \\
\text { to povezuju i } \\
\text { sa činjenicom } \\
\text { da nude } \\
\text { mogućnost } \\
\text { života u nekoj } \\
\text { drugoj državi. } \\
\text { Treba da } \\
\text { odgovore na } \\
\text { tri w-pitanja } \\
\text { koja se } \\
\text { odnose na } \\
\text { tekst. }\end{array}$ & $\begin{array}{l}\text { Razvijanje } \\
\text { vještine čitanja i } \\
\text { razumijevanja; } \\
\text { Uvježbavanje } \\
\text { izgovora; } \\
\text { Kultura i } \\
\text { civilizacija: } \\
\text { mogućnost } \\
\text { odlaska i rada u } \\
\text { inostranstvu. }\end{array}$ & $\begin{array}{l}\text { Komunikativni } \\
\text { pristup }\end{array}$ & $\begin{array}{l}\text { Autentičan tekst iz } \\
\text { svakodnevnog života o } \\
\text { radu i životu u } \\
\text { inostranstvu. }\end{array}$ \\
\hline $\begin{array}{l}\text { Str. } 71 . \text { Modul } 8 \\
\text { Projekt } \\
\text { Landeskunde } \\
\text { Zadatak } 2 .\end{array}$ & $\begin{array}{l}\text { Učenici treba } \\
\text { da se } \\
\text { informiraju } \\
\text { na internetu i } \\
\text { pronađu neku } \\
\text { agenciju koja } \\
\text { nudi slično } \\
\text { kao u zadatku } \\
\text { br. } 1, \text { te da }\end{array}$ & $\begin{array}{l}\text { Razvijanje } \\
\text { vještine čitanja i } \\
\text { razumijevanja; } \\
\text { Razvijanje } \\
\text { vještine pisanja; } \\
\text { Razvijanje } \\
\text { vještine govora; } \\
\text { Kultura i } \\
\text { civilizacija: život i }\end{array}$ & $\begin{array}{l}\text { Komunikativni } \\
\text { pristup }\end{array}$ & $\begin{array}{l}\text { Autentičan tekst, } \\
\text { svakidašnja tema, koja } \\
\text { animira učenike da } \\
\text { komuniciraju, istražuju i } \\
\text { uče. }\end{array}$ \\
\hline
\end{tabular}




odgovore na rad u inostranstvu.
pitanja, a
nakon toga da
na osnovu
odgovora
nađu
odgovarajuce
slike uz
odgovore, te
da to sve
prezentiraju
pred
razredom.

Tabela 1. Analiza udžbenika Menschen A2

Ako posmatramo sprovedeno istraživanje, možemo zaključiti da su prisutna sva tri pristupa unutar modula kojim se obrađuju isključivo elementi kulture i civilizacije. Kognitivni i komunikativni pristup sa po šest zadataka, a interkulturalni pristup se tretira sa pet zadataka, s tim da je kod jednog zadatka prisutan i interkulturalni i komunikativni pristup. Kada posmatramo zastupljenost elemenata kulture i civilizacije u kompletnom udžbeniku Menschen A2, uzimajući u obzir ukupan broj stranica $(100+100$ str.) i broj stranica u udžbeniku koje pripadaju modulu Projekt Landeskunde (4 + 4 str.), onda dolazimo do zaključka da je taj segment zastupljen sa samo $4 \%$ od ukupnog broja stranica. Treba istaći da je analiza udžbenika posevećena samo poglavljima udžbenika koji tretiraju isključivo temu kultura i civilizacija, te da nisu uzete u obzir ostale lekcije u kojima se kultura implicitno obrađuje (npr. kod najobičnijih situacija kao što je kupovina hrane, naručivanje u nekom ugostiteljskom objektu i slično).

Sljedeća tabela detaljno prikazuje rezultate do kojih smo došli:

\begin{tabular}{|c|c|c|c|}
\hline \multicolumn{2}{|c|}{$\begin{array}{c}\text { Zastupljenost elemenata kulture i } \\
\text { civilizacije u udžbeniku Menschen } A 2\end{array}$} & \multicolumn{2}{|c|}{$\begin{array}{c}\text { Zastupljenost elemenata kulture i } \\
\text { civilizacije prema pristupu u dijelu } \\
\text { Modul Landeskunde udžbenika } \\
\text { Menschen } A 2\end{array}$} \\
\hline Menschen A2/1 & $4 \%$ & Kognitivni pristup & $35,5 \%$ \\
\hline \multirow[t]{2}{*}{ Menschen A2/2 } & $4 \%$ & $\begin{array}{l}\text { Komunikativni } \\
\text { pristup }\end{array}$ & $35,5 \%$ \\
\hline & & $\begin{array}{l}\text { Interkulturalni } \\
\text { pristup }\end{array}$ & $29 \%$ \\
\hline
\end{tabular}

Tabela 2. Rezultati analize udžbenika Menschen A2 


\section{ZAKLJUČAK}

Udžbenik Menschen A2 uz svaki modul, a ima ih osam, nudi jedno poglavlje, na jednoj stranici, koje obrađuje elemente kulture i civilizacije. Ako pogledamo zastupljenost pristupa (kognitivni, komunikativni, interkulturalni), onda primjećujemo da su autori udžbenika vodili računa o tome da sva tri pristupa budu prisutna, i onaj kojim se prenose činjenice o zemlji jezika cilja (npr. geografske činjenice o Švicarskoj), i tekstovi svakodnevnice (npr. pohađanje kurseva njemačkog jezika), te informacije koje pomažu da razumijemo ono drugo i drugačije, te da poredimo sa onim što je naše (npr. poređenje klime u domovini i nekoj drugoj zemlji), sa ciljem objektivnog stajališta i tolerancije, te razbijanja eventualnih predrasuda. Uzmemo li u obzir broj stranica kompletnog udžbenika, dolazimo do zaključka da poseban odjeljak u udžbeniku sa fokusom na elemente kulture i civilizacije zauzima tek $4 \%$. Međutim, ako bismo analizirali kompletan udžbenik, ovaj procenat bi bio veći, jer se kultura obrađuje i implicitno, s obzirom da je suština komunikativnog pristupa da se, na osnovu različitih komunikativnih situacija, prenosi kultura svakodnevnice.

$\mathrm{Na}$ osnovu sprovedenog istraživanja možemo zaključiti da udžbenik Menschen A2 uzima u obzir stajališta da su kultura i civilizacija sastavni dio učenja stranog jezika, te da ih se kao takve ne treba zapostavljati, što odgovara postavkama komunikativne metode koja zagovara jezičke i izvanjezičke dimenzije kao obligatorne komponente nastave stranih jezika sa ciljem izbjegavanja nesporazuma zbog različitosti u kulturama.

\section{LITERATURA}

Altmayer, C. (2017). Landeskunde im Globalisierungskontext: Wozu noch Kultur im DaF-Unterricht?, in Kulturelles Lernen im DaF/DaZ-Unterricht. Paradigmawechsel im der Landeskunde, ur. P. Hasse i Michaela Höller (Göttingen: Universitätsverlag): 3-23.

Braun-Podeschwa, J., Habersach, C., \& Pude, A. (2014). Menschen. Deutsch als Fremdsprache. Kursbuch B1.1. München: Hueber.

Habersack, C., Pude, A., \& Specht, F. (2013). Menschen. A2, Kursbuch, Menschen : Deutsch als Fremdsprache; Kursbuch (1. Aufl.). Ismaning: Hueber.

Hansen, K. P. (2000). Kultur und Kulturwissenschaft. Tübingen: UTB.

Heyd, G. (1991). Deutsch lehren. Grundwissen für den Unterricht Deutsch als Fremdsprache. Frankfurt am Main: Diesterweg. 
Hofstede, G. (1991). Allemaal andersdenkenden. Omgaan met cultuurverschillen. Amsterdam: Contact.

Holzmüller, H. H. (1997). Kulturstandards- ein operationales Konzept zur Entwicklung kultursensitiven Managements, in Interkulturelles Management, ur. J. Engelhart (Wiesbaden: Springer): 55-74.

Keller, G. (1983). Grundlegung einer neuen Kulturkunde als Orientierungsrahmen für Lehrerausbildung und Unterrichtsprozess. Neusprachliche Mitteilungen 4: 200-209.

Klein, W. (1992). Zweitsprachenerwerb. Königstein im Taunus: Athenäums. Kramsch, C. (2000). Language and Culture. Oxford: Oxford University Press.

Pauldrach, A. (1994). Eine undendliche Geschichte. Anmerkungen zur Situation der Landeskunde in den 90er Jahren. Fredmsprache Deutsch. Zeitschrift für die Praxis des Deutschunterrichts 6: 4-15.

Picht, R. (1989). Kultur- und Landeswissenschaften, in Handbuch Fremdsprachenunterricht, ur. Bausch, K. R., Christ, H., Hüllen, W., Krumm, H. J. (Tübingen: Francke Verlag): 54-60.

Schwend, J. (1997). Kultur, Kulturwissenschaft und Translation, in Transfer, Übersetzen-Dolmetschen-Interkulturalität. 50 Jahre Fachbereich Angewandtze Sprachwissenschaft der Johannes Gutenberg-Universität Mainz in Germersheim, ur. Drescher, H. W., Görke, L. \& Herber, J. (Frankfurt am Main: Peter Lang): 263-278.

Thimme, C. (1995). Interkulturelle Landeskunde. Ein kritischer Beitrag zur aktuellen LandeskundeDiskussion. Deutsch als Fremdsprache 32 (3): 131-137.

\section{ELEKTRONSKI IZVORI}

Goethe-Institut. Pristupljeno 20. 5. 2020. URL: <http://www.goethe.de/ins/by/ pro/lewis/didakt/Didaktisierung_Deutschland_ von_oben_fuer_Kinder_ erzaelt_Mai.pdf>.

Sprachportal. Pristupljeno 21. 5. 2020.

URL:

<https://sprachportal.integrationsfonds.at/fileadmin/user_upload/2015/Mat erialien\%20Schwerpunkt\%20Deutsch/Kommunikation_im_Alltag.pdf $>$.

Youtube. Pristupljeno 23. 5. 2020. URL: 〈https://www.youtube.com/watch?time_ continue $=2 \& v=K w T 0 J d k W-u E \&$ feature $=e m b \_t i t l e>$. 
Belma S. Polić

University of Zenica

Faculty of Philosophy, Department of German Language and Literature

\section{ELEMENTS OF CULTURE AND CIVILIZATION IN A GERMAN LANGUAGE TEXTBOOK MENSCHEN A2}

\section{Summary}

It is a well-known fact that an understanding of the cultural specifics of a society also contributes to successful communication between people. Since antiquity there has been talk about the importance of cultural content when learning and teaching some of the foreign languages. In foreign language teaching, culture and teaching content related to the cultural segment of a society have been neglected for a long time. What could be found in the textbooks were factual data on the foreign country and its population. Recently, the methodology of foreign language teaching has been more intensively dedicated to the integration of interculturalism in foreign language teaching, which is also aided by the phenomenon of increasing globalization, which does not recognize borders and limitations, stereotypes, ethnocentrism, prejudices, etc. Without teaching culture teaching a foreign language is incomplete, since human nature does not exist separately from culture and, therefore, learning a foreign language at the same time implies understanding the nature of other people. The paper: 1) presents the role of elements of culture and civilization in foreign language teaching, in order to notice their importance and obligatoriness in the teaching process, since language and culture are closely related components of human existence; 2) analyzes the textbook Menschen A2, which is used in teaching German as a foreign language, to show the representation of elements of culture and civilization in the textbook; 3) classifies the elements of culture and civilization excerpted from the analyzed textbook in order to answer the question: are all three key approaches (cognitive, communicative and intercultural) represented in the treatment of civilization in the analyzed textbook?

Key words: German language, didactics, foreign language teaching methodology, culture and civilization.

Primljeno: 16. 6. 2020.

Prihvaćeno: 7. 8. 2020. 